\title{
Article
}

\section{Heated Tobacco Products and Nicotine Pouches: A Survey of People with Experience of Smoking and/or Vaping in the UK}

\author{
Leonie S. Brose ${ }^{1,2, * \mathbb{D}}$, Máirtín S. McDermott ${ }^{1}$ and Ann McNeill ${ }^{1,2}$ (D) \\ 1 Addictions, Institute of Psychiatry, Psychology and Neuroscience, King's College London, 4 Windsor Walk, \\ London SE5 8BB, UK; mairtin.mcdermott@gmail.com (M.S.M.); ann.mcneill@kcl.ac.uk (A.M.) \\ 2 SPECTRUM Consortium, Edinburgh EH8 9YL, UK \\ * Correspondence: leonie.brose@kcl.ac.uk
}

check for updates

Citation: Brose, L.S.; McDermott, M.S.; McNeill, A. Heated Tobacco Products and Nicotine Pouches: A Survey of People with Experience of Smoking and/or Vaping in the UK. Int. J. Environ. Res. Public Health 2021, 18, 8852. https://doi.org/10.3390/ ijerph18168852

Academic Editor:

Stefano Campostrini

Received: 28 June 2021

Accepted: 4 August 2021

Published: 22 August 2021

Publisher's Note: MDPI stays neutral with regard to jurisdictional claims in published maps and institutional affiliations.

Copyright: (c) 2021 by the authors. Licensee MDPI, Basel, Switzerland. This article is an open access article distributed under the terms and conditions of the Creative Commons Attribution (CC BY) license (https:/ / creativecommons.org/licenses/by/ $4.0 /)$.

\begin{abstract}
Background: To gauge the public health impact of new nicotine products, information is needed on use among different populations. Aims were to assess in adults who smoked, vaped, did both or had recently stopped: (1) awareness, ever and current use of heated tobacco products (HTPs) and nicotine pouches (NP), (2) characteristics associated with ever use, (3) reasons for use of and satisfaction with HTPs, (4) characteristics associated with interest in use of HTPs. Methods: Online survey in the UK in 2019, $n=3883$. (1) Proportion aware, ever and current ( $\geq$ monthly) use; (2) ever use regressed onto socio-demographics and smoking/vaping; (3) frequency of reasons for HTP use and satisfaction; (4) interest in trying HTPs regressed onto socio-demographics and smoking/vaping status. Results: Awareness was 34.8\% for HTP and 15.9\% for NP; current use was 3.2\% and 2.7\%. Being $<45$ years, higher education, living in London and currently both smoking and vaping were associated with ever having used the products. Curiosity was the most common reason for HTP use $(79.8 \%)$ and $72.0 \%$ of ever HTP users found them at least as satisfying as smoking. Among those not currently using HTPs, $48.5 \%$ expressed any interest-lower among those aged over 65 and higher among those smoking and vaping. Conclusions: In this sample of adults with a history of nicotine use, very few currently used heated tobacco products or nicotine pouches. Satisfaction with and interest in HTPs were substantial. The low level of use is unlikely to substantially reduce the public health impact of smoking.
\end{abstract}

Keywords: nicotine; novel tobacco products; smoking; inequalities

\section{Introduction}

Cigarette smoking remains the most common way of consuming nicotine [1] and the second most important risk factor for death and loss of healthy life years globally [2,3], almost entirely due to the effects of combustion, not nicotine [4]. Harm from smoking is concentrated among groups with other disadvantages such as low education or poor physical or mental health [5-7] and thus increases inequities.

New categories of nicotine-containing products have emerged in recent years, including heated tobacco products (HTPs) and nicotine pouches. HTPs are electronic devices that heat processed tobacco with the aim of avoiding combustion [8]. There are different types of HTPs, each produced by one of the major tobacco companies: IQOS (Philip Morris International), the first HTP to become available in the UK from late 2016 [8], and glo (British American Tobacco) both heat tobacco sticks to produce an aerosol that the user can inhale; iFuse (BAT) and Ploom Tech (Japan Tobacco International) heat an e-liquid to produce an aerosol which then passes over the tobacco. Philip Morris International had requested a risk modification and an exposure modification order for IQOS in the US. The US Food and Drug Administration (FDA) has authorised IQOS to be marketed as a modified risk tobacco product [9]. The FDA concluded that, based on current evidence on exposure in the absence of long-term studies, switching completely from smoking to IQOS reduced exposure to harmful or potentially harmful chemicals. However, they did not 
approve that IQOS use reduces the risk of tobacco-related diseases or reduces harm relative to continued cigarette smoking. Notably, in Japan, the introduction and rapid increase in use of HTP $[10,11]$ has led to an acceleration in the decline of cigarette sales [12,13].

Nicotine pouches entered the UK market in the period 2018-2019. In appearance, they resemble snus, a type of tobacco pouch widely used in Sweden with substantially reduced harm compared with smoking $[14,15]$. However, in contrast to snus, nicotine pouches do not contain tobacco but nicotine-containing powder [16]. They are designed to be placed into the mouth to release nicotine. Brands include ZYN (Swedish Match), LYFT (British American Tobacco) and Nordic Spirit (Japan Tobacco International). Very little research on these products has been published. One study compared pharmacokinetics of ZYN with two other oral products, snus (tobacco pouches) and wet snuff (chewing tobacco). Results indicated that ZYN could deliver nicotine into the bloodstream as quickly and to a similar extent as the existing smokeless products with no significant adverse effects [17]. For Zonnic, an older type of nicotine pouch, trials found that compared with nicotine gum, nicotine pouches were as effective or more effective at reducing craving and favoured by smokers [18,19].

The net public health effect from the introduction of alternative nicotine products depends on the degree to which use is less harmful than smoking, whether people who smoke switch to other products, whether people who used to smoke take up new products, whether people who would not have used any nicotine or tobacco product take up new products and whether this diverts them from or attracts them to using more harmful products $[20,21]$. Understanding factors associated with use of novel products has important implications for gauging their public health effects [22].

There is some evidence on prevalence of and characteristics associated with HTP (mostly IQOS) use from nationally representative surveys in some countries. In the US in $2017,1.1 \%$ of adults reported current use [23]. In Great Britain in 2017, 0.8\% [24] and in $2019,0.6 \%$ of adults indicated any current use [25]. In Germany in the period 2016-2017, $0.3 \%$ of current and recent smokers reported current HTP use [26]. In Japan in 2018, 2.7\% of adults reported at least monthly use [27]. In South Korea in 2018, 4.4\% of adults reported current use [28]. Use was very rare [24,27] or non-existent [28] among those who had not smoked, higher among those with higher education or income $[24,26,28]$ and higher among younger age groups [24,26,28], although this was not the case in Japan [27]. A survey in Australia, Canada, England and the US in 2018 among current and former smokers and/or vapers found overall just under one-third were aware of HTPs, $2.4 \%$ had ever tried and $0.9 \%$ were current at least monthly users, with trial and current use higher among those who also smoked and vaped (8.4\%) [29].

Almost no information is available on the use of nicotine pouches. One US study surveyed 1266 users of ZYN. Among them, 43\% were former tobacco users (either of smokeless tobacco, cigarettes, both cigarettes and smokeless tobacco, or former e-cigarette and other combustible users), 26\% were current smokeless tobacco users, 19\% dual users, $8 \%$ current smokers, and $4 \%$ of had not smoked at least 100 cigarettes or regularly used other tobacco products, although all were currently using one or more tobacco products [21]. An analysis of smokeless tobacco products (including tobacco-free nicotine pouches) sold in US convenience stores reported that nicotine pouches accounted for $4 \%$ of unit sales by 2019 [30].

\section{Aims}

1. To assess awareness, ever and current use of HTPs and nicotine pouches in a UK sample of people who smoked, vaped, did both or had recently stopped.

2. To assess respondent characteristics associated with ever use of HTPs and nicotine pouches.

3. To assess reasons for use of and satisfaction with HTPs among ever and current HTP users. 
4. To assess interest in use of heated tobacco among those who had never used or tried them up to a few times and characteristics associated with interest.

\section{Materials and Methods}

This cross-sectional study used self-reported data from one wave of a UK longitudinal online survey of adults who were current or former smokers and/or vapers. Survey participants were recruited through an online consumer panel of Ipsos Interactive Services. Data were collected and managed by Ipsos and anonymised to the researchers. The survey imposed quotas for age, gender and geographical region to ensure that the sample was representative. The first wave of data collection was in 2012 and the sample has been replenished twice. In wave 6 in September/October 2019, 1000 continuing and 2883 new participants (3883 in total) completed the survey.

\subsection{Measures}

Socio-demographics included gender (male, female), age (18-24, 25-34, 35-44, 45-54, 55-65, over 65), education (no university, some university), ethnicity using 2011 UK census categories [31], and UK region (England: North East, North West, Yorkshire and The Humber, West Midlands, East Midlands, East of England, South West, South East, Greater London; Wales; Scotland; Northern Ireland).

Measures related to different nicotine or tobacco products are provided in Box 1. Definitions of the different products were provided at the beginning of the survey and were available for each question. In the survey, the term 'Heat-not-burn tobacco products (also known as Heated Tobacco Products)' was used. Smoking and vaping status were assessed and combined into one measure (smoking only, smoking and vaping, vaping only, currently not smoking or vaping).

Box 1. Nicotine product questions.

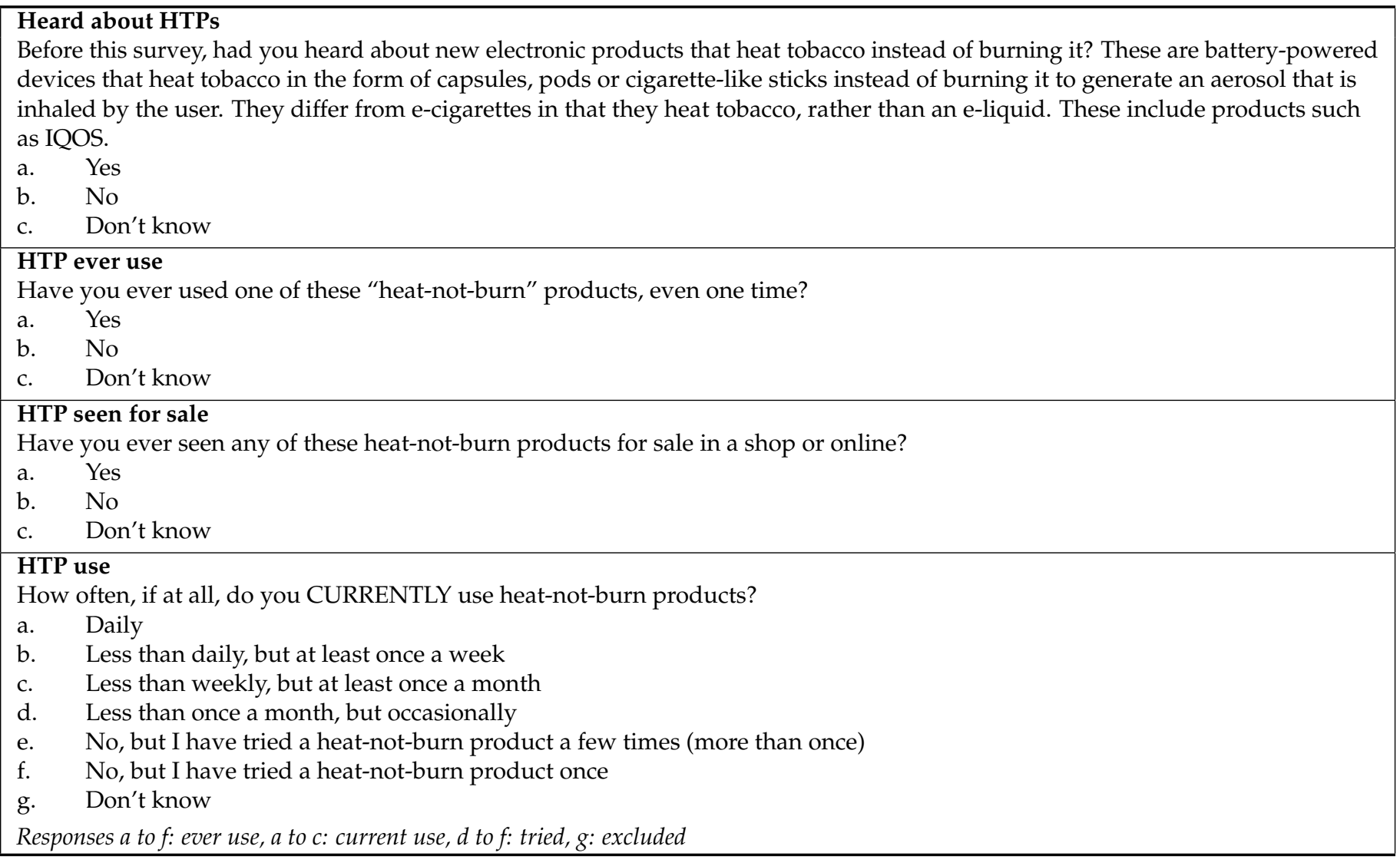


Box 1. Cont.

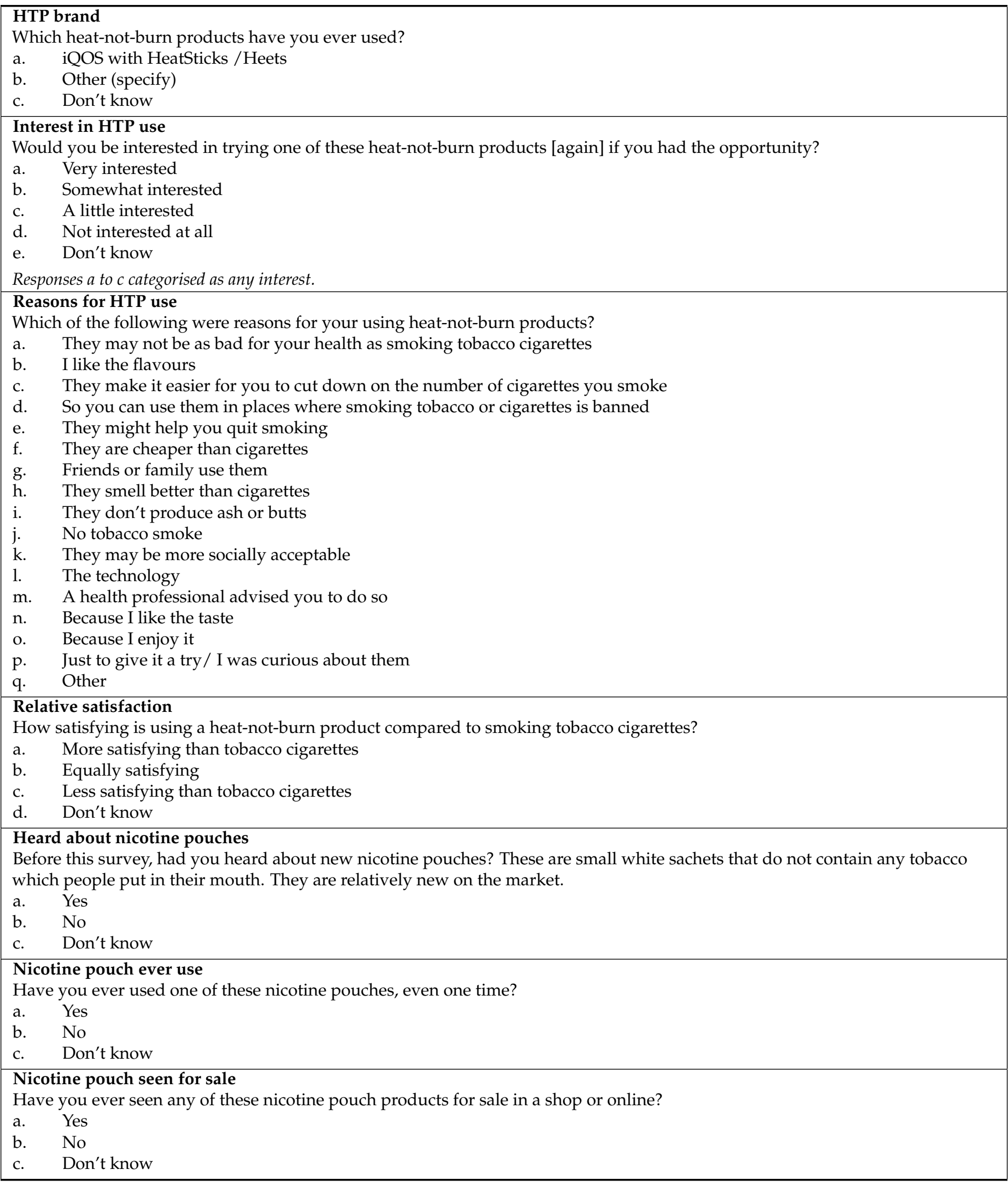


Box 1. Cont.

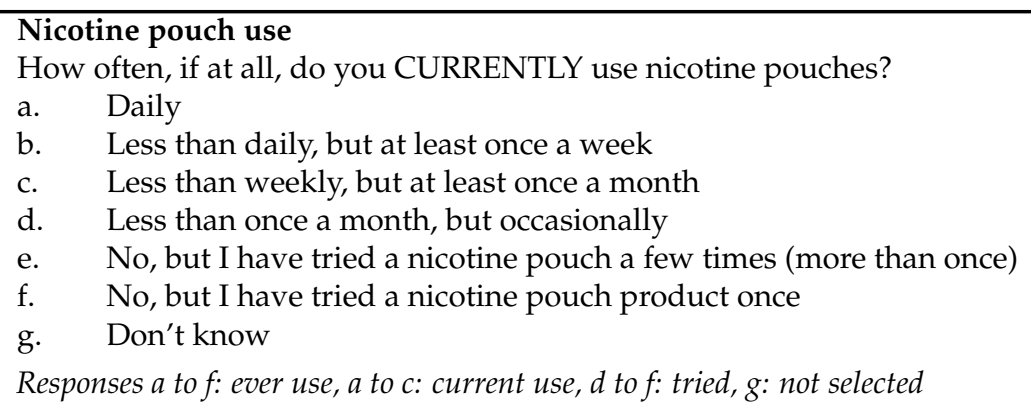

\section{Smoking status ${ }^{1}$}

In this question, we are referring only to tobacco cigarettes and other smoked tobacco products (not vaping devices, e-cigarettes or heat-not-burn tobacco products). Could you please tell us which of the following best applies to you now?

a. I smoke tobacco cigarettes (including hand-rolled) every day

b. I smoke tobacco cigarettes (including hand-rolled), but not every day

c. I do not smoke tobacco cigarettes at all, but I do smoke tobacco of some kind (e.g., pipe, cigar or shisha)

d. I stopped smoking tobacco products (cigarettes, pipes, cigars, shisha etc) completely within the last 12 months

e. I stopped smoking tobacco products (cigarettes, pipes, cigars, shisha etc) completely over 1 year ago

f. I have never been a smoker (of cigarettes, pipes, cigars shisha etc)

\section{Vaping status ${ }^{1}$}

Could you please tell us which of the following best applies to you now?

a. I currently vape/ use e-cigarettes daily

b. I currently vape/ use e-cigarettes but not every day

c. I have tried vaping/ an e-cigarette once or a few times

d. I stopped vaping/ using e-cigarettes completely within the last 12 months

e. I stopped vaping/ using e-cigarettes completely over 1 year ago

f. I have never vaped/ used e-cigarettes

${ }^{1}$ Combined smoking and vaping status: Smoking status a to $\mathrm{c}$ and vaping status $\mathrm{c}$ to $\mathrm{f}=$ Smoking only; Smoking status a to $\mathrm{c}$ and vaping status $\mathrm{a}$ to $\mathrm{b}=$ Smoking and vaping; Smoking status $\mathrm{d}$ to $\mathrm{f}$ and vaping status $\mathrm{a}$ to $\mathrm{b}$ : Vaping only; Smoking status $\mathrm{d}$ to $\mathrm{f}$ and vaping status $\mathrm{C}$ to f: Not currently smoking or vaping.

\subsection{Sample}

All 3883 respondents were included to address aims 1 and 2 . To address aim 3 , the 242 respondents who had ever used HTPs were included for reasons for use and the subset of 193 respondents who had used HTPs more than once to describe satisfaction. To address aim 4, the 1199 respondents who had not used HTPs or had tried them up to a few times only were included in analysis.

\subsection{Analyses}

To address aim 1, the prevalence of having heard of, ever use and at least monthly us (current use) of HTP and nicotine pouches was described.

To address aim 2, associations between ever use of HTPs and nicotine pouches and socio-demographics and smoking and vaping status were assessed using bivariate and multivariable logistic regressions. Multivariable logistic regressions included gender, age, education, ethnicity, region and smoking and vaping status. Only ever use was used in regressions because current use was low. The results section reports multivariable (adjusted) analysis unless otherwise reported.

To address aim 3, frequency of responses to a list of possible reasons for use were described and compared using chi-square statistics for current users of HTPs and for those who had only tried HTPs or were using it less than monthly. Satisfaction with HTPs compared with cigarettes was described for those two groups.

To address aim 4, proportions interested in trying HTPs were described; bivariate and multivariable logistic regressions were used to assess associations with socio-demographics and smoking and vaping status. Multivariable logistic regressions included gender, age, education, ethnicity, region and smoking and vaping status and adjusted results are re- 
ported unless otherwise reported. Information on reasons for use, satisfaction or interest in use was not available for nicotine pouches.

\section{Results}

The sample was split evenly between men and women and covered all age groups. The majority (90.9\%) identified as white and $45.9 \%$ had started or completed university education. Over two-thirds (69.4\%) were current smokers and 37.3\% were current vapers (Table 1). Combining those two measures showed that almost half of the sample were smoking but not vaping $(46.9 \%)$, almost a quarter were smoking and vaping $(22.4 \%)$, with the rest split between those vaping but not smoking $(14.8 \%)$ and those neither smoking or vaping $(15.8 \%)$.

Table 1. Sample description, $n=3883$.

\begin{tabular}{|c|c|c|c|c|c|}
\hline Socio-Demographics & $\%$ & $n$ & Nicotine Product Use & $\%$ & $n$ \\
\hline Gender & & & Smoking & & \\
\hline Male & 50.3 & 1955 & Daily cigarettes & 48.0 & 1864 \\
\hline Female & 49.7 & 1928 & Non-daily cigarettes & 15.7 & 610 \\
\hline Age & & & Other tobacco & 5.6 & 219 \\
\hline $18-24$ & 8.7 & 339 & Stopped smoking in last year & 9.8 & 380 \\
\hline $25-34$ & 18.1 & 703 & Stopped smoking over a year ago & 19.1 & 742 \\
\hline $35-44$ & 21.2 & 823 & Never smoked & 1.8 & 68 \\
\hline $45-54$ & 22.5 & 872 & Vaping & & \\
\hline $55-65$ & 17.0 & 659 & Daily & 24.4 & 949 \\
\hline Over 65 & 12.5 & 487 & Non-daily & 12.8 & 498 \\
\hline Ethnicity & & & Tried a few times & 23.1 & 897 \\
\hline UK white & 84.2 & 3269 & Stopped vaping in last year & 5.2 & 201 \\
\hline Other white & 6.6 & 256 & Stopped vaping over a year ago & 5.8 & 226 \\
\hline Mixed & 2.6 & 102 & Never vaped & 28.6 & 1112 \\
\hline Asian & 4.0 & 154 & Combined smoking and vaping & & \\
\hline Black & 1.5 & 59 & Smoking only & 46.9 & 1822 \\
\hline Other, not reported & 1.1 & 43 & Smoking and vaping & 22.4 & 871 \\
\hline Education & & & Vaping only & 14.8 & 576 \\
\hline No university/ not reported & 54.1 & 2101 & Not smoking or vaping & 15.8 & 614 \\
\hline Some university & 45.9 & 1782 & Heated Tobacco & & \\
\hline UK region & & & Ever heard & 34.8 & 1353 \\
\hline England excluding London & 69.1 & 2683 & Seen for sale & 10.1 & 392 \\
\hline Greater London & 15.3 & 596 & Ever used & 6.2 & 242 \\
\hline Wales & 4.5 & 176 & Current frequency of use ${ }^{1}$ & & \\
\hline Scotland & 8.9 & 344 & Daily $^{2}$ & 18.6 & 45 \\
\hline \multirow{18}{*}{ Northern Ireland } & 2.2 & 84 & Less than daily, at least once a week ${ }^{2}$ & 14.5 & 35 \\
\hline & & & Less than weekly, at least once a month ${ }^{2}$ & 18.2 & 44 \\
\hline & & & Less than monthly & 12.4 & 30 \\
\hline & & & Tried a few times & 16.1 & 39 \\
\hline & & & Tried once & 16.5 & 40 \\
\hline & & & Don't know & 3.7 & 9 \\
\hline & & & Nicotine pouches & & \\
\hline & & & Ever heard & 15.9 & 616 \\
\hline & & & Seen for sale & 3.1 & 122 \\
\hline & & & Ever used & 4.4 & 171 \\
\hline & & & Current frequency of use ${ }^{1}$ & & \\
\hline & & & Daily ${ }^{2}$ & 20.5 & 35 \\
\hline & & & Less than daily, at least once a week ${ }^{2}$ & 19.9 & 34 \\
\hline & & & Less than weekly, at least once a month ${ }^{2}$ & 19.9 & 34 \\
\hline & & & Less than monthly & 9.9 & 17 \\
\hline & & & Tried a few times & 11.7 & 20 \\
\hline & & & Tried once & 18.1 & 31 \\
\hline & & & Don't know & 0 & 0 \\
\hline
\end{tabular}

${ }^{1}$ Among ever users. ${ }^{2}$ Categorised as current use. 


\subsection{Awareness, Ever Use and Current Use of HTP and Nicotine Pouches}

Over one-third (34.8\%) had heard about HTPs and $15.9 \%$ had heard about nicotine pouches. Fewer had ever seen HTPs $(10.1 \%)$ or nicotine pouches $(3.1 \%)$ for sale in shops or online. Heated tobacco products had ever been used by $6.2 \%$ of the sample, including $3.2 \%$ current users. Nicotine pouches had ever been used by $4.4 \%$, including $2.7 \%$ current users. Of those who had ever used HTPs, $32.6 \%$ had used them only once or a few times; for nicotine pouches, this was $29.8 \%$ of all ever users (Table 1 ).

\subsection{Characteristics Associated with Ever Use of HTPs and Nicotine Pouches}

Men and women were equally likely to have ever used HTPs. Age groups under 45 years were more likely to have ever used than the oldest age group. Respondents with some university education were more likely to have ever used HTPs, and those from London were more likely to have ever used HTPs than respondents from other parts of England with Wales, Scotland and Northern Ireland similar to England (excluding London). Respondents currently vaping and smoking were more likely to have ever used HTPs than those who were exclusively smoking; those currently not smoking or vaping and those exclusively vaping had similar levels of ever use as those exclusively smoking (Table 2). In unadjusted analysis (Supplemental Table S1), there was also an association with ethnicity, with respondents categorised as not white more likely to have ever used.

Table 2. Prevalence of current and ever use (includes current use) of heated tobacco products and nicotine pouches, associations between ever use and respondent characteristics and prevalence of and associations with interest in trying HTPs.

\begin{tabular}{|c|c|c|c|c|c|c|c|c|c|c|c|}
\hline \multirow[b]{3}{*}{ Condor } & \multicolumn{7}{|c|}{ Heated Tobacco Products } & \multicolumn{4}{|c|}{ Nicotine Pouches } \\
\hline & \multicolumn{2}{|c|}{$\begin{array}{c}\text { Prevalence, } \\
n=3883\end{array}$} & \multicolumn{2}{|c|}{$\begin{array}{l}\text { Adjusted Associations } \\
\text { for Ever Use }{ }^{1}\end{array}$} & \multirow[t]{2}{*}{$\begin{array}{l}\text { Interest, } \\
n=1199\end{array}$} & \multicolumn{2}{|c|}{$\begin{array}{c}\text { Adjusted Associations } \\
\text { for Interest }\end{array}$} & \multicolumn{2}{|c|}{$\begin{array}{l}\text { Prevalence, } \\
n=3883\end{array}$} & \multicolumn{2}{|c|}{$\begin{array}{l}\text { Adjusted Associations } \\
\text { for Ever Use }^{1}\end{array}$} \\
\hline & Current & Ever & OR (95 CI) & $p$ & & OR (95 CI) & $p$ & Current & Ever & OR (95 CI) & $p$ \\
\hline Male & 3.5 & 6.2 & $\begin{array}{c}1.17 \\
(0.89-1.55)\end{array}$ & 0.26 & 46.8 & $\begin{array}{c}0.98 \\
(0.76-1.27)\end{array}$ & 0.89 & 2.9 & 5.1 & $\begin{array}{c}1.79 \\
(1.29-2.49)\end{array}$ & 0.001 \\
\hline $\begin{array}{l}\text { Female } \\
\text { Age }\end{array}$ & 2.9 & 6.2 & Ref & & 50.8 & Ref & & 2.4 & 3.7 & Ref & \\
\hline $18-24$ & 6.5 & 10.9 & $\begin{array}{c}5.89 \\
(2.55-13.58)\end{array}$ & $<0.001$ & 59.1 & $\begin{array}{c}3.60 \\
(1.99-6.53)\end{array}$ & $<0.001$ & 5.3 & 7.4 & $\begin{array}{c}7.53 \\
(2.55-22.24)\end{array}$ & $<0.001$ \\
\hline $25-34$ & 6.7 & 11.2 & $\begin{array}{c}5.36 \\
(2.41-11.92)\end{array}$ & $<0.001$ & 64.5 & $\begin{array}{c}4.26 \\
(2.58-7.04)\end{array}$ & $<0.001$ & 6.1 & 9.0 & $\begin{array}{c}8.04 \\
(2.85-22.69)\end{array}$ & $<0.001$ \\
\hline $35-44$ & 4.4 & 8.4 & $\begin{array}{c}4.60 \\
(2.07-10.2)\end{array}$ & $<0.001$ & 58.0 & $\begin{array}{c}3.70 \\
(2.30-5.96)\end{array}$ & $<0.001$ & 3.9 & 6.2 & $\begin{array}{c}6.09 \\
(2.16-17.15)\end{array}$ & 0.001 \\
\hline $45-54$ & 0.9 & 3.2 & $\begin{array}{c}2.05 \\
(0.88-4.75)\end{array}$ & 0.096 & 41.7 & $\begin{array}{c}2.00 \\
(1.28-3.12)\end{array}$ & 0.002 & 0.6 & 2.1 & $\begin{array}{c}2.33 \\
(0.78-6.96)\end{array}$ & 0.131 \\
\hline $55-65$ & 1.4 & 3.3 & $\begin{array}{c}2.06 \\
(0.87-4.89)\end{array}$ & 0.101 & 42.6 & $\begin{array}{c}1.90 \\
(1.21-2.99)\end{array}$ & 0.006 & 0.8 & 1.5 & $\begin{array}{c}1.54 \\
(0.48-4.97)\end{array}$ & 0.468 \\
\hline $\begin{array}{l}\text { Over } 65 \\
\text { Ethnicity }\end{array}$ & 0.4 & 1.4 & Ref & & 27.7 & Ref & & 5.3 & 0.8 & Ref & \\
\hline Not white & 5.6 & 10.3 & $\begin{array}{c}0.97 \\
(0.65-1.43)\end{array}$ & 0.871 & 53.6 & $\begin{array}{c}0.86 \\
(0.56-1.32)\end{array}$ & 0.49 & 5.6 & 8.1 & $\begin{array}{c}1.03 \\
(0.66-1.59)\end{array}$ & 0.908 \\
\hline $\begin{array}{l}\text { White } \\
\text { Education }\end{array}$ & 3.0 & 5.8 & Ref & & 47.9 & Ref & & 2.4 & 4.0 & Ref & \\
\hline Some university & 5.3 & 9.6 & $\begin{array}{c}2.11 \\
(1.56-2.84)\end{array}$ & $<0.001$ & 53.9 & $\begin{array}{c}1.13 \\
(0.88-1.44)\end{array}$ & 0.34 & 4.7 & 7.0 & $\begin{array}{c}2.09 \\
(1.45-3.00)\end{array}$ & $<0.001$ \\
\hline $\begin{array}{l}\text { No university } \\
\text { Region }\end{array}$ & 1.4 & 3.4 & Ref & & 43.4 & Ref & & 1.0 & 2.2 & Ref & \\
\hline Greater London & 7.9 & 11.9 & $\begin{array}{c}1.75 \\
(1.28-2.40)\end{array}$ & $<0.001$ & 54.4 & $\begin{array}{c}1.28 \\
(0.92-1.77)\end{array}$ & 0.140 & 7.0 & 9.2 & $\begin{array}{c}2.10 \\
(1.45-3.03)\end{array}$ & $<0.001$ \\
\hline Wales & 0 & 2.3 & $\begin{array}{c}0.42 \\
(0.15-1.16)\end{array}$ & 0.094 & 48.1 & $\begin{array}{c}0.95 \\
(0.53-1.72)\end{array}$ & 0.87 & 0.6 & 1.1 & $\begin{array}{c}0.34 \\
(0.08-1.39)\end{array}$ & 0.132 \\
\hline Scotland & 2.0 & 3.8 & $\begin{array}{c}0.66 \\
(0.37-1.19)\end{array}$ & 0.169 & 38.9 & $\begin{array}{c}0.82 \\
(0.51-1.30)\end{array}$ & 0.40 & 2.6 & 4.9 & $\begin{array}{c}1.54 \\
(0.89-2.66)\end{array}$ & 0.122 \\
\hline Northern Ireland & 1.2 & 3.6 & $\begin{array}{c}0.64 \\
(0.20-2.07)\end{array}$ & 0.451 & 56.7 & $\begin{array}{c}2.19 \\
(0.96-5.02)\end{array}$ & 0.063 & 7.0 & 3.6 & $\begin{array}{c}1.13 \\
(0.34-3.71)\end{array}$ & 0.845 \\
\hline $\begin{array}{l}\text { England excl London } \\
\text { Smoking / Vaping }\end{array}$ & 2.6 & 5.6 & Ref & & 47.6 & Ref & & 1.9 & 3.5 & $\begin{array}{l}\text { Ref } \\
\text { Ref }\end{array}$ & \\
\hline Not smoking or vaping & 1.6 & 3.4 & $\begin{array}{c}0.67 \\
(0.41-1.09)\end{array}$ & 0.107 & 23.3 & $\begin{array}{c}0.29 \\
(0.19-0.44)\end{array}$ & $<0.001$ & 2.0 & 3.4 & $\begin{array}{c}1.05 \\
(0.62-1.77)\end{array}$ & 0.86 \\
\hline Smoking and vaping & 8.6 & 13.2 & $\begin{array}{c}2.26 \\
(1.67-3.07)\end{array}$ & $<0.001$ & 62.6 & $\begin{array}{c}1.39 \\
(1.02-1.89)\end{array}$ & 0.038 & 6.8 & 9.5 & $\begin{array}{c}2.25 \\
(1.56-3.25)\end{array}$ & $<0.001$ \\
\hline Vaping only & 1.6 & 3.5 & $\begin{array}{c}0.76 \\
(0.46-1.26)\end{array}$ & 0.29 & 42.9 & $\begin{array}{c}0.77 \\
(0.55-1.06)\end{array}$ & 0.109 & 0.9 & 2.1 & $\begin{array}{c}0.72 \\
(0.38-1.36)\end{array}$ & 0.31 \\
\hline Smoking only & 1.7 & 4.7 & Ref & & 49.9 & Ref & & 1.5 & 3.0 & Ref & \\
\hline
\end{tabular}


For ever use of nicotine pouches, there was a gender difference with men more likely to have ever used. The associations with age, ethnicity, education, region and smoking/vaping had a similar pattern to those for HTP ever use. Groups more likely to have ever used were those aged under 45 , those with university education and those from London. Those currently vaping and smoking were more likely to have ever used nicotine pouches than those who were exclusively smoking; those currently not smoking or vaping and those exclusively vaping had similar levels of ever use as those exclusively smoking (Table 2). Additionally, as with HTPs, an association with ethnicity was only apparent in unadjusted analysis (Supplemental Table S1).

\subsection{Reasons for Use of HTPs and Satisfaction}

Among those who had ever tried HTPs, the most commonly endorsed reason was 'Just to give it a try/I was curious' (79.8\%) and with the exception of 'A health professional advised you to do so' and 'other', all reasons were endorsed by more than half of ever users (Table 3). Current users were more likely to support each reason than those who had only tried once or a few times, with the exception of 'Just to give it a try/I was curious' where those who had tried were more likely to agree, and 'No tobacco smoke' and 'They don't produce ash or butts' where differences were not significant (Table 3).

Table 3. Reasons for use of HTPs and satisfaction relative to smoking, $n=242$ ever users.

\begin{tabular}{|c|c|c|c|c|c|}
\hline & \multicolumn{3}{|c|}{ Agreement, \% } & \multicolumn{2}{|c|}{$\begin{array}{c}\text { Comparison } \\
\text { Current vs. Tried }\end{array}$} \\
\hline & Overall & Current Users & Tried & $x^{2}$ & $p$ \\
\hline Which of the following were reasons for your using heat-not-burn products? & $n=242$ & $n=124$ & $n=109$ & & \\
\hline Just to give it a try / I was curious about them & 79.8 & 75.0 & 85.3 & 6.78 & 0.028 \\
\hline They smell better than cigarettes & 70.8 & 76.6 & 64.2 & 6.13 & 0.046 \\
\hline No tobacco smoke & 69.4 & 67.9 & 68.7 & 0.37 & 0.89 \\
\hline They don't produce ash or butts & 66.5 & 62.9 & 70.0 & 5.31 & 0.071 \\
\hline They may be more socially acceptable & 66.1 & 74.2 & 56.9 & 7.82 & 0.019 \\
\hline They make it easier for you to cut down on the number of cigarettes you smoke & 65.2 & 75.8 & 53.2 & 13.55 & 0.001 \\
\hline I like the flavours & 64.4 & 81.5 & 45.0 & 34.32 & $<0.001$ \\
\hline They may not be as bad for your health as smoking tobacco cigarettes & 63.9 & 66.9 & 60.6 & 11.8 & 0.002 \\
\hline The technology & 63.5 & 71.8 & 54.1 & 8.14 & 0.015 \\
\hline They might help you quit smoking & 61.8 & 66.9 & 56.0 & 8.11 & 0.016 \\
\hline Because I enjoy it & 60.1 & 71.0 & 47.7 & 15.06 & $<0.001$ \\
\hline So you can use them in places where smoking tobacco or cigarettes is banned & 59.2 & 66.1 & 51.4 & 8.08 & 0.018 \\
\hline Because I like the taste & 58.8 & 75.0 & 40.4 & 29.11 & $<0.001$ \\
\hline Friends or family use them & 58.4 & 67.7 & 47.7 & 10.64 & 0.004 \\
\hline They are cheaper than cigarettes & 54.5 & 65.3 & 42.2 & 16.69 & $<0.001$ \\
\hline A health professional advised you to do so & 43.3 & 62.9 & 21.2 & 42.28 & $<0.001$ \\
\hline Other & 30.5 & 42.7 & 16.5 & 30.52 & $<0.001$ \\
\hline \multicolumn{6}{|l|}{$\begin{array}{c}\text { How satisfying is using a heat-not-burn product compared to smoking tobacco } \\
\text { cigarettes? }\end{array}$} \\
\hline More satisfying & 29.0 & 37.1 & 14.5 & & \\
\hline Equally satisfying & 43.0 & 50.0 & 30.4 & 40.15 & $<0.001$ \\
\hline Less satisfying & 25.4 & 12.1 & 49.3 & & \\
\hline Don't know & 2.6 & 0.8 & 5.8 & & \\
\hline
\end{tabular}

${ }^{1} n=40$ who tried once excluded.

Overall, $72.0 \%$ of those who had used HTPs more than once rated HTPs as at least as satisfying as smoking (Table 3). Perceived satisfaction relative to smoking was higher among those currently using HTPs ( $87.1 \%$ as least as satisfying) than among those who had tried a few times or were using HTPs less than monthly (44.9\%, Table 3$)$.

\subsection{Interest in Use of HTPs}

Among those who had never used HTPs or tried once or a few times, $48.5 \%$ reported any interest in trying HTPs (10.5\% very interested, $17.8 \%$ somewhat interested, $20.2 \%$ a little interested), whereas $47.0 \%$ were not at all interested and $4.6 \%$ did not know. All age groups up to the age of 65 were more likely to report any interest in trying HTPs than those aged over 65 . Those not smoking or vaping were less likely to report any interest 
and those currently vaping and smoking more likely to report any interest than those currently exclusively smoking (Table 2). In unadjusted analysis, those with some university education were also more likely to report any interest (Supplemental Table S1).

\section{Discussion}

In this sample comprising smokers, recent ex-smokers and vapers, a minority were aware of new nicotine products, with very small minorities having experience of using them. Approximately one-third were aware of HTPs, with ever and current use being just over six and three per cent, respectively. Corresponding figures for nicotine pouches were just over one in six being aware and ever and current use being just over four and just below three per cent, respectively. Being under 45 years, having higher education, living in London and currently concurrently smoking and vaping were associated with ever having used HTPs or nicotine pouches; men were also more likely to have ever used nicotine pouches. Curiosity was the most common reason for use or trial of HTPs and a majority of those who had ever used them found them at least as satisfying as smoking. Nearly half of those not currently using HTPs expressed interest in using them: interest was lower among those aged over 65 than in all other age groups and among those not smoking or vaping compared with those smoking only but higher among those smoking and vaping.

Awareness of HTPs appears to have increased in Great Britain since 2017, when awareness was between $10 \%$ and $18 \%$ of current or recent past smokers/vapers [24], although differences between surveys and measures make comparisons difficult. Overall, current use appears not to have increased (for example 2.0\% among current smokers in 2017 compared with 1.7\% among exclusive smokers in this survey). Prevalence among smokers, recent ex-smokers and vapers in the present survey was consistent with previous surveys [29].

Despite low awareness, current use of nicotine pouches was similar to current use of HTP in this sample. In comparison to other countries, such as Japan and South Korea [27,28], use of HTPs is much lower, although this might also reflect reduced accessibility of vaping products in those countries compared with Great Britain. It is also of note that not all ever users of nicotine pouches reported having seen them for sale, suggesting trial of other people's products or free samples given out as marketing strategy. There are no prior surveys in Great Britain or other countries of nicotine pouch use for comparison.

The characteristics of those with some experience of using HTPs and nicotine pouches were remarkably consistent, with those under 45 , those with at least some university experience and those who were both smoking and vaping being more likely to have some experience. The socio-economic differences for HTPs may reflect the retail cost of HTPs, which for a starter pack is approximately $£ 40$ (approximately $\$ 54$ as of December 2020). However, cheaper cost was a reason for using that current HTP users were more likely to state than ever users. This reflects that ongoing costs are lower as once the HTP device has been purchased, a pack of tobacco sticks are approximately half the price of a pack of cigarettes. The price of a tin of 20 nicotine pouches is approximately equivalent to a pack of 20 cigarettes, so the socio-economic differences may instead reflect differential accessibility /marketing to different socio-economic groups or areas, or that smokers are looking for cheaper substitutes for smoking overall.

That people who both smoked and vaped, but not those exclusively smoking or vaping, were more likely to have tried HTPs and pouches may reflect their desire to find a product to help them stop smoking given vaping has not resulted in their stopping smoking. Similarly, smokers and vapers who were not HTP users were more likely to be interested in trying HTP compared with exclusive smokers. Current HTP users were indeed more likely to choose quitting smoking as a reason for use compared to HTP triers. However, nearly all the reasons supplied in the questionnaire were more likely to be endorsed by current users compared to triers, and several other reasons were more popular than quitting smoking for current users. 
Overall, that nearly $90 \%$ of current HTP users found HTPs at least as satisfying as cigarettes suggests that HTPs could be a successful substitute for cigarettes in those using them to quit smoking. Fewer triers ( $45 \%)$ found HTPs as satisfying as cigarettes suggesting that their impact differs across users.

To our knowledge, this is the first study to provide information about use of nicotine pouches and detailed evidence on HTP use and interest, but results need to be viewed in the light of some limitations. Results provide a snapshot of the situation at the time in what is a constantly moving field. Data were from a survey with respondents selfreporting all measures and no verification of responses was possible. Particularly as the products of interest are relatively new, confusion may have occurred with other products such as vaping products or chewing tobacco pouches. The survey did, however, include explanations and pictures at the beginning of the survey and these could be accessed throughout the survey to reduce any confusion. Despite an overall large sample, the low prevalence of use meant we were only able to assess associations with ever use, not the more relevant current use and sample sizes were small for some analyses. Middle aged adults were over-represented, providing less information particularly about older adults. The sample was restricted to adults with experience of nicotine use, so cannot provide information about uptake or interest in these products among those who have never used nicotine products or smoked.

To assess public health impact, future research should therefore assess interest and use among nicotine-naïve groups as well as the effects of use of HTPs or nicotine pouches on smoking cessation or reduction. If these products help smokers to stop and/or are significantly less harmful, then more needs to be done to increase their use among exclusive smokers. Regulatory restrictions may then need to be reconsidered, although a crosscountry study only found small differences between countries varying even on legal availability [29].

\section{Conclusions}

In this sample of adults with a history of nicotine use, very few currently used heated tobacco products or nicotine pouches. Satisfaction with and interest in HTPs were substantial. The low level of use is unlikely to substantially reduce the public health impact of smoking.

Supplementary Materials: The following are available online at https://www.mdpi.com/article/10 $.3390 /$ ijerph18168852/s1, Table S1. Bivariate associations between ever use of, and interest in HTPs, ever use of nicotine pouches and socio-demographics and smoking and vaping status. $n=3883$ for ever use; $n=1199$ for interest.

Author Contributions: Conceptualization, L.S.B., M.S.M. and A.M.; methodology, L.S.B., M.S.M. and A.M.; formal analysis L.S.B.; investigation, L.S.B., M.S.M. and A.M.; data curation, M.S.M.; writing — original draft preparation, L.S.B.; writing—review and editing, L.S.B., M.S.M. and A.M.; funding acquisition, L.S.B. and A.M. All authors have read and agreed to the published version of the manuscript.

Funding: The survey was funded by a Cancer Research UK grant (C25586/A28505). L.S.B. and A.M. are members of SPECTRUM, a UK Prevention Research Partnership Consortium. UKPRP is an initiative funded by the UK Research and Innovation Councils, the Department of Health and Social Care (England) and the UK devolved administrations, and leading health research charities.

Ethics Approval: King's College London Research Ethics Committee MRA-18/19-13459.

Acknowledgments: We thank Sara Hitchman for help with questions on heated tobacco products and for her contribution to earlier waves of this survey. We thank Timea Partos for her contributions to the development and conduct of this survey. We thank Ms Ceren Turkkolu for initial analysis.

Conflicts of Interest: The authors declare no conflict of interest. 


\section{References}

1. World Health Organization. Tobacco. 2020. Available online: https://www.who.int/news-room/fact-sheets/detail/tobacco (accessed on 18 December 2020).

2. G.B.D. Risk Factors Collaborators. Global burden of 87 risk factors in 204 countries and territories, 1990-2019: A systematic analysis for the Global Burden of Disease Study 2019. Lancet 2020, 396, 1223-1249.

3. Institute for Health Metrics and Evaluation. GBD Compare 2020. Available online: http://ihmeuw.org/5bq5 (accessed on 18 December 2020).

4. Drug \& Therapeutics Bulletin Editorial Office. Republished: Nicotine and health. BMJ 2014, 349, 0264rep.

5. Mackenbach, J.P.; Kulhanova, I.; Menvielle, G.; Bopp, M.; Borrell, C.; Costa, G.; Deboosere, P.; Esnaola, S.; Kalediene, R.; Kovacs, K.; et al. Trends in inequalities in premature mortality: A study of 3.2 million deaths in 13 European countries. J. Epidemiol. Community Health 2015, 69, 207-217. [CrossRef]

6. Richardson, S.; McNeill, A.; Brose, L.S. Smoking and quitting behaviours by mental health conditions in Great Britain (1993-2014). Addict. Behav. 2019, 90, 14-19. [CrossRef]

7. World Health Organization Regional Office for Europe. European Tobacco Use; Trends Report; WHO Regional Office for Europe: Copenhagen, Denmark, 2019.

8. Simonavicius, E.; McNeill, A.; Shahab, L.; Brose, L.S. Heat-not-burn tobacco products: A systematic literature review. Tob. Control. 2019, 28, 582-594. [CrossRef] [PubMed]

9. US Food and Drug Administration. FDA Authorizes Marketing of IQOS Tobacco Heating System with 'Reduced Exposure' Information. 2020. Available online: https://www.fda.gov/news-events/press-announcements/fda-authorizes-marketingiqos-tobacco-heating-system-reduced-exposure-information (accessed on 7 July 2020).

10. Hori, A.; Tabuchi, T.; Kunugita, N. Rapid increase in heated tobacco product (HTP) use from 2015 to 2019: From the Japan 'Society and New Tobacco' Internet Survey (JASTIS). Tob. Control 2020, 30, 474-475. [CrossRef]

11. Odani, S.; Tabuchi, T. Prevalence of heated tobacco product use in Japan: The 2020 JASTIS study. Tob. Control. 2021. [CrossRef]

12. Cummings, K.M.; Nahhas, G.J.; Sweanor, D.T. What Is Accounting for the Rapid Decline in Cigarette Sales in Japan? Int. J. Environ. Res. Public Health 2020, 17, 3570. [CrossRef] [PubMed]

13. Stoklosa, M.; Cahn, Z.; Liber, A.; Nargis, N.; Drope, J. Effect of IQOS introduction on cigarette sales: Evidence of decline and replacement. Tob. Control. 2020, 29, 381-387. [CrossRef] [PubMed]

14. Lee, P.N. Epidemiological evidence relating snus to health-An updated review based on recent publications. Harm Reduct. J. 2013, 10, 36. [CrossRef] [PubMed]

15. Hatsukami, D.K.; Carroll, D.M. Tobacco harm reduction: Past history, current controversies and a proposed approach for the future. Prev. Med. 2020, 140, 106099. [CrossRef]

16. Robichaud, M.O.; Seidenberg, A.B.; Byron, M.J. Tobacco companies introduce 'tobacco-free' nicotine pouches. Tob. Control. 2019, 29, e145-e146. [CrossRef]

17. Lunell, E.; Fagerstrom, K.; Hughes, J.; Pendrill, R. Pharmacokinetic Comparison of a Novel Non-tobacco-Based Nicotine Pouch (ZYN) With Conventional, Tobacco-Based Swedish Snus and American Moist Snuff. Nicotine Tob. Res. 2020, 22, 1757-1763. [CrossRef] [PubMed]

18. Caldwell, B.; Burgess, C.; Crane, J. Randomized crossover trial of the acceptability of snus, nicotine gum, and Zonnic therapy for smoking reduction in heavy smokers. Nicotine Tob. Res. 2010, 12, 179-183. [CrossRef] [PubMed]

19. Thornley, S.; McRobbie, H.; Lin, R.B.; Bullen, C.; Hajek, P.; Laugesen, M.; Senior, H.; Whittaker, R. A single-blind, randomized, crossover trial of the effects of a nicotine pouch on the relief of tobacco withdrawal symptoms and user satisfaction. Nicotine Tob. Res. 2009, 11, 715-721. [CrossRef]

20. Levy, D.T.; Cummings, K.M.; Villanti, A.C.; Niaura, R.; Abrams, D.B.; Fong, G.T.; Borland, R. A framework for evaluating the public health impact of e-cigarettes and other vaporized nicotine products. Addiction 2017, 112, 8-17. [CrossRef] [PubMed]

21. Plurphanswat, N.; Hughes, J.R.; Fagerstrom, K.; Rodu, B. Initial Information on a Novel Nicotine Product. Am. J. Addict. Am. Acad. Psychiatr. Alcohol. Addict. 2020, 29, 279-286. [CrossRef]

22. Dunbar, M.S.; Seelam, R.; Tucker, J.S.; Rodriguez, A.; Shih, R.A.; D'Amico, E.J. Correlates of Awareness and Use of Heated Tobacco Products in a Sample of US Young Adults in 2018-2019. Nicotine Tob. Res. 2020, 22, 2178-2187. [CrossRef] [PubMed]

23. Nyman, A.L.; Weaver, S.R.; Popova, L.; Pechacek, T.F.; Huang, J.; Ashley, D.L.; Eriksen, M.P. Awareness and use of heated tobacco products among US adults, 2016-2017. Tob. Control. 2018, 27, s55-s61. [CrossRef]

24. Brose, L.S.; Simonavicius, E.; Cheeseman, H. Awareness and Use of 'Heat-not-burn' Tobacco Products in Great Britain. Tob. Regul. Sci. 2018, 4, 44-50. [CrossRef]

25. McNeill, A.; Brose, L.S.; Calder, R.; Bauld, L.; Robson, D. Vaping in England: An Evidence Update Including Mental Health and Pregnancy, March 2020; A Report Commissioned by Public Health England; Public Health England: London, UK, 2020.

26. Kotz, D.; Kastaun, S. E-cigarettes and heat-not-burn products: Representative data on consumer behaviour and associated factors in the German population (the DEBRA study). Bundesgesundheitsblatt Gesundh. Gesundh. 2018, 61, 1407-1414. [CrossRef]

27. Sutanto, E.; Miller, C.; Smith, D.M.; O'Connor, R.J.; Quah, A.C.K.; Cummings, K.M.; Xu, S.; Fong, G.T.; Hyland, A.; Ouimet, J.; et al. Prevalence, Use Behaviors, and Preferences among Users of Heated Tobacco Products: Findings from the 2018 ITC Japan Survey. Int. J. Environ. Res. Public Health 2019, 16, 4630. [CrossRef] 
28. Kim, S.H.; Cho, H.J. Prevalence and correlates of current use of heated tobacco products among a nationally representative sample of Korean adults: Results from a cross-sectional study. Tob. Induc. Dis. 2020, 18, 66. [CrossRef] [PubMed]

29. Miller, C.R.; Sutanto, E.; Smith, D.M.; Hitchman, S.C.; Gravely, S.; Yong, H.H.; Borland, R.; O'Connor, R.J.; Cummings, K.M.; Fong, G.T.; et al. Awareness, trial and use of heated tobacco products among adult cigarette smokers and e-cigarette users: Findings from the 2018 ITC Four Country Smoking and Vaping Survey. Tob. Control. 2020. [CrossRef] [PubMed]

30. Delnevo, C.D.; Hrywna, M.; Miller Lo, E.J.; Wackowski, O.A. Examining market trends in smokeless tobacco sales in the United States: 2011-2019. Nicotine Tob. Res. 2021, 23, 1420-1424. [CrossRef] [PubMed]

31. Office for National Statistics. 2011 Census Variable and Classification Information. Available online: https://www.ons.gov.uk/ census/2011census/2011censusdata/2011censususerguide/variablesandclassifications (accessed on 18 December 2020). 